\title{
DISTÚRBIOS DO RITMO CARDÍACO
}

\author{
CARDIAC ARRITHMIAS
}

Antônio Pazin Filho'; José Paulo Pyntiá2 \& André Schmidt ${ }^{1}$

\begin{abstract}
${ }^{1}$ Docentes. Departamento de Clínica Médica. Faculdade de Medicina de Ribeirão Preto - USP. ${ }^{2}$ Médico Assistente. Hospital das Clínicas da Faculdade Medicina de Ribeirão Preto - USP.

CorResPondênCIA: Prof. Dr. Antonio Pazin Filho. Centro de Estudos de Emergências em Saúde - Unidade de Emergência - HCFMRP-USP. Rua Bernardino de Campos, 1000. Ribeirão Preto - SP. CEP: 14015-030. e-mail: apazin@fmrp.usp.br
\end{abstract}

PAZIN FILHO A; PYNTIÁ JP \& SCHMIDT A. Distúrbios do ritmo cardíaco. Medicina, Ribeirão Preto, 36: 151-162, abr./dez. 2003.

RESUMO - São revisados conceitos fundamentais para o tratamento dos distúrbios do ritmo cardíaco na sala de urgência. O tratamento das taquicardias, das bradicardias e, em particular, da fibrilação e do flutter atrial é revisto em maior detalhe devido a sua prevalência.

UNITERMOS - Arritmia. Taquicardia. Bradicardia. Fibrilação Atrial. Flutter Atrial.

\section{1- INTRODUÇÃO}

O termo Distúrbios do Ritmo Cardíaco (DRC) é designação mais apropriada do que o termo arritmias, comumente empregado, haja vista que arritmia significa ausência de ritmo, o que não corresponde à realidade para a quase totalidade desses distúrbios. Sob essa denominação, encontram-se alterações cuja gravidade nem sempre caracterizam emergência. Nesta revisão, serão incluídos os distúrbios do ritmo cardíaco que necessitem de abordagem imediata, no contexto da sala de urgência. Faremos, primeiro, algumas considerações gerais sobre o diagnóstico e tratamento desses distúrbios e, depois, abordaremos os distúrbios mais freqüentes, em separado.

\section{2- CONSIDERAÇÕES GERAIS}

Os Distúrbios do Ritmo Cardíaco podem caracterizar, do ponto de vista clínico, desde situações assintomáticas até outras muito graves, como por exemplo, a parada cardíaca.

No primeiro contexto, o do paciente assintomático, o distúrbio pode ser identificado por acaso, quando o paciente é avaliado por outra queixa não relacio- nada. A ampla gama de distúrbios do ritmo cardíaco permite que possam existir, nesse contexto distúrbios, que não necessitem de tratamento e, também, distúrbios que exijam tratamento imediato, devido ao risco de evolução para situação mais crítica. A identificação de com qual situação estamos lidando pode ser facilitada pela identificação do distúrbio, o que nem sempre é fácil para o clínico geral. Como regra, duas situações exigem cuidados imediatos: taquicardias ventriculares sustentadas e bloqueios atrioventriculares de alto grau (segundo grau Mobitz II e terceiro grau).

A segunda situação, do paciente que se apresenta sintomático, pode parecer mais confortável para o clínico geral. Afinal de contas, a decisão de se tratar ou não, em princípio, já foi tomada. No entanto, vários distúrbios do ritmo podem estar presentes, concomitantemente a um sintoma, e não serem diretamente responsáveis por eles, situação que deve ser conduzida como foi descrito, anteriormente, para o paciente assintomático.

A preocupação em se determinar se o distúrbio do ritmo é, ou não, responsável pelos sintomas, e se deve ou não ser tratado, é legítima. O tratamento das taquicardias estáveis, geralmente, envolve o uso de medicações antiarrítmicas. Esse grupo de medicações 
compreende grande variedade de medicamentos com mecanismos de atuação distintos, mas que apresentam característica comum: pró-arritmia ${ }^{(1)}$. Trata-se da capacidade dessas medicações de induzir distúrbios do ritmo cardíaco. Em outras palavras, sempre que utilizarmos uma medicação antiarrítmica, existe potencial não desprezível de que ela possa induzir novo distúrbio do ritmo cardíaco, ou agravar o até então vigente. Se estivermos utilizando a medicação, num contexto em que o distúrbio do ritmo cardíaco seja responsável pelo quadro clínico do paciente, ou tenha o potencial de evoluir para situação mais crítica, esse risco se justifica. Numa situação reversa, estaremos submetendo o paciente a risco considerável, que aumenta, exponencialmente, ao associarmos duas medicações antiarrítmicas.

Frente a tais considerações, cabe a pergunta de quando atribuir a um distúrbio do ritmo cardíaco os sintomas apresentados pelo paciente. É uma pergunta de difícil resposta, haja vista o grande espectro de apresentação clínica desses distúrbios, como, por exemplo, palpitações, serem ocasionados, também, por outros distúrbios. Outro complicador importante é o fato de que várias entidades clínicas podem ocasionar alterações do ritmo cardíaco. Como exemplos, perda sangüínea aguda ou situações de choque podem ocasionar taquicardia sinusal reacional, enquanto bradicardia com graus variados de bloqueio atrioventricular são ocasionadas por hipoxemia. Nessas situações, a conduta deve visar corrigir a causa básica (choque, hipoxemia, etc), e não o distúrbio de ritmo cardíaco, o que poderia até ser prejudicial, na maioria dos casos. A Tabela I classifica os distúrbios do ritmo cardíaco como causas cardíacas e não cardíacas, para auxílio no diagnóstico diferencial.

Por todo o exposto, deve-se, sempre, excluir que o distúrbio do ritmo cardíaco não seja secundário a outra afecção. Na maioria dessas situações, a correção do fator precipitante corrigirá, também, o distúrbio do ritmo cardíaco sem que sejam necessárias outras medidas ou incluídas as medicações antiarrítmicas.

A principal complicação de um distúrbio do ritmo cardíaco é a diminuição do débito cardíaco efetivo, diminuição que pode ser sentida em diversos sistemas, sendo que quatro deles adquirem importância fundamental, por implicarem em maior morbimortalidade (Tabela II). A presença desses sintomas e de sinais de hipoperfusão aponta para a gravidade do quadro clínico e alerta o médico para a conduta rápida. Esses sinais acontecem quer nas taquicardias quer nas bradicardias. No contexto das taquicardias, a conduta é direcionada para a cardioversão elétrica, enquanto que, nas bradicardias, é mandatória a colocação de marca-passo transcutâneo provisório, até que se estabeleça acesso venoso para implantação do marca-passo transvenoso.

\section{Tabela I - Causas Cardíacas e Extracardíacas de Distúrbios do Ritmo Cardíaco.}

\author{
Causas Cardíacas \\ - Insuficiência coronariana aguda (IAM) \\ - Miocardites \\ - Endocardite bacteriana; abscessos miocárdicos \\ - Pericardite aguda \\ - Lesão miocárdica traumática \\ - Miocardiopatias (Doença de Chagas) \\ - Esclerose do sistema de condução \\ - Doenças do colágeno \\ - Limitação crônica do fluxo aéreo (DPOC) \\ - Anomalias congênitas \\ Causas Extracardíacas \\ - Aumento de catecolaminas endógenas: dor, ansiedade, \\ agitação, febre, anemia. \\ - Hipoxemia \\ - Distúrbios hidroeletrolíticos \\ - Distúrbios acidobásicos \\ - Sepse \\ - Hipotermia \\ - Hormonais (hipo ou hipertireoidismo) \\ - Neoplasias: intracraniana, mediastinal \\ - Neurológicas: vagotonia, reação vasovagal, trauma, AVC, \\ poliradiculoneuropatias. \\ - Medicamentosas: digitálicos, xantinas, anfetaminas, lítio, \\ fenotiazidas, antidepressivos, aminas vasoativas, etc.
}


Tabela II - Critérios de Instabilidade dos Distúrbios do Ritmo Cardíaco

\section{Sistema acometido Sintomas e sinais}

1. Sistema Nervoso Central

Alteração do nível de consciência nos mais variados graus, desde confusão mental até coma.

2. Circulação Coronariana Dor precordial, do tipo anginosa, de intensidade e irradiação variáveis.

3. Pulmões

Dispnéia de repouso, de grau leve até edema agudo de pulmão. Ao exame físico, podem ser identificados estertores em bases pulmonares.

4. Sistema Circulatório

Sinais de choque circulatório, com hipotensão arterial e sinais de baixa perfusão tecidual (sudorese fria, diminuição do enchimento capilar, etc).

É natural que o sistema cardiovascular procure se adaptar frente à alteração hemodinâmica, decorrente de distúrbio do ritmo cardíaco. A integridade desse sistema é de fundamental importância no quadro clínico. Embora a bomba cardíaca tenha papel fundamental no processo, a adaptação envolve outros componentes do sistema, como a resistência vascular periférica, determinada pelo tônus vascular. Essas adaptações podem ser responsáveis pela apresentação oligossintomática de alguns pacientes e, de fundamental importância, podem ser influenciadas pela medida terapêutica empregada, principalmente a de caráter farmacológico. Vários antiarrítmicos afetam a resistência vascular periférica (exemplo: bloqueadores dos canais de cálcio) ou o inotropismo cardíaco (exemplo: betabloqueadores). Portanto, deve-se considerar o estado do sistema cardiovascular e as possíveis adaptações que se encontram em curso para a escolha da intervenção terapêutica. Em situações emergenciais, a avaliação da integridade do sistema cardiovascular pode ser limitada, haja vista a impossibilidade de se obter exames de maior complexidade. Não se deve menosprezar, no entanto, a contribuição da anamnese e do exame físico. Pacientes com história e sinais clínicos de insuficiência cardíaca, antecedentes de infarto agudo do miocárdio ou miocardiopatias, apresentam, provavelmente, menor capacidade de adaptação e devem ser conduzidos com maior cuidado.

Paralelamente à definição da etiologia e do grau de acometimento do distúrbio do ritmo cardíaco, outra preocupação deve ser a de documentá-lo o melhor possível $^{(2)}$. É claro que, frente às situações emergenciais, em que o paciente apresenta qualquer dos sintomas listados na Tabela II, a documentação pode ser limitada ou proibitiva. No entanto, deve-se ter presen- te que, para muitos pacientes, essa pode ser a única oportunidade de se documentar o distúrbio para que, fora da crise, possa ser avaliado pelo especialista e possibilitar o tratamento adequado. Por exemplo, pacientes com taquicardia supraventricular, decorrente da existência de um feixe anômalo de condução, podem se queixar freqüentemente de palpitações, mas nunca terem tido oportunidade de documentar, num eletrocardiograma, a taquicardia. Essa documentação pode limitar a investigação, muitas vezes, morosa e invasiva, a que tais pacientes poderiam, eventualmente, ser submetidos.

A documentação do distúrbio do ritmo pode ser efetuada pelo eletrocardiograma de doze derivações. Em alguns casos, a utilização de derivações especiais, como a derivação de Lewis e Golub, ou mesmo, a derivação transesofágica podem ser empregadas, se o paciente se mantiver estável (Figura 1). Recursos adicionais, como o aumento da velocidade do eletrocardiógrafo ou o aumento da amplitude dos complexos, podem favorecer a interpretação (Figura 2).

Algumas considerações, ainda, devem ser feitas quanto ao emprego das medicações antiarrítmicas. Para cada medicação a ser feita, deve-se sempre considerar: quando fazer (indicação), como fazer (farmacocinética e farmacodinâmica), porque está sendo feita (mecanismo de ação) e atenção com os efeitos deletérios. Na Tabela III, pode-se encontrar, de modo resumido, as principais medicações antiarrítmicas, de acordo com os citados princípios. Na elaboração da tabela, utilizou-se a apresentação disponível na farmácia da U.E. - HCFMRP-USP.

A abordagem geral dos distúrbios do ritmo cardíaco pode ser encontrada na Figura 3, seguida de comentário mais detalhado de cada uma das situações. 

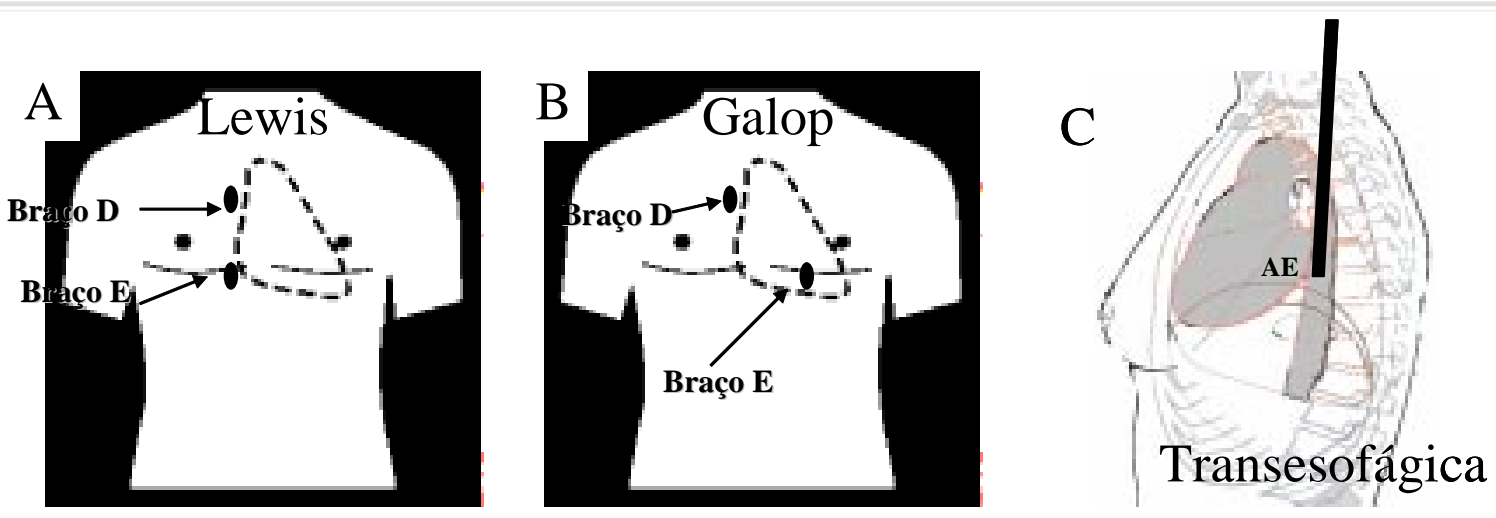

Figura 1 - Derivações não convencionais para diagnóstico dos distúrbios do ritmo. A e B - Derivações de Lewis e Galop - Constituemse na colocação dos cabos da derivação D1 do eletrocardiograma nos pontos demonstrados na figura. C - Derivação esofágica - a colocação de um eletrodo no esôfago, permite melhor documentação da atividade atrial, devido à proximidade com o átrio esquerdo.

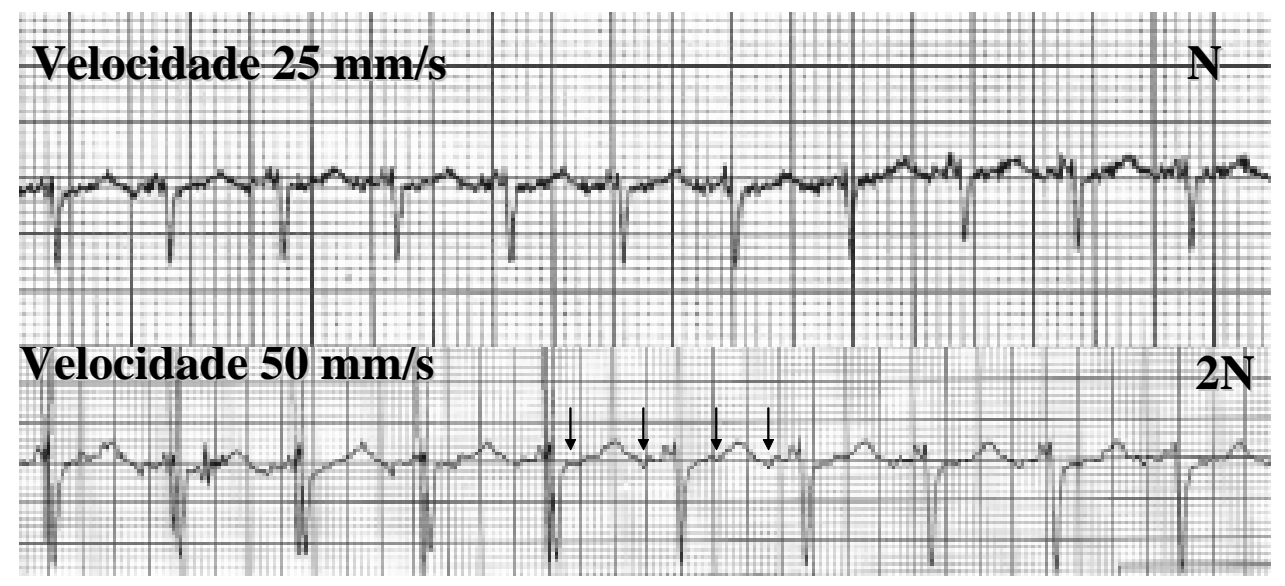

Figura 2 - Traçados eletrocardiográficos, na derivação D2, obtidos do mesmo paciente. No traçado inferior, aumentouse a velocidade do papel e a amplitude dos complexos, permitindo a identificação de onda f (setas), do flutter atrial

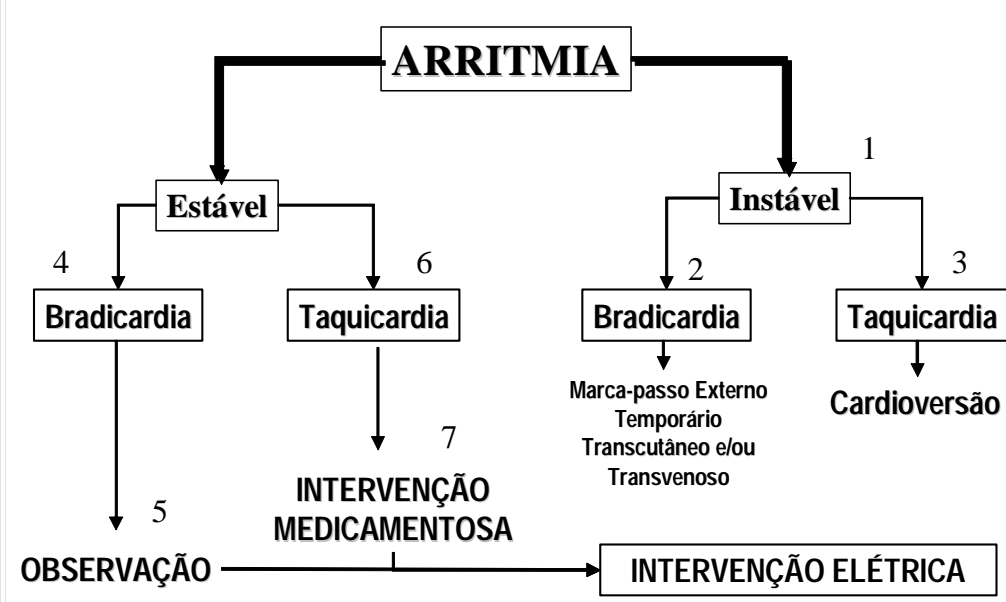

Figura 3 - Abordagem geral dos distúrbios do ritmo cardíaco.
1 - O primeiro ponto na avaliação de distúrbio do ritmo cardíaco é a averiguação dos critérios de instabilidade (Vide Tabela II). Caso estejam presentes, a intervenção envolverá um tratamento elétrico, no caso das bradicardias, marca-passo externo (2) e no caso das taquicardias, cardioversão (3).

2 - No caso de bradicardias instáveis, o tratamento pode envolver, além da intervenção elétrica, as opções listadas na Figura 8.

4 - No caso de bradicardias estáveis, em princípio, o tratamento envolverá apenas a observação do paciente (5), a não ser que se identifique algum bloqueio atrioventricular de grau avançado (BAV Mobitz II ou BAVT). (Vide Figura 9). Em tais casos, o tratamento envolve intervenção elétrica (2).

6 - A intervenção medicamentosa com antiarrítmicos só deve ser utilizada em taquicardias estáveis.

7 - O uso de antiarrítmicos deve ser baseado no tipo da taquicardia (Figuras 5,6 e 7) e levar em consideração a função ventricular. Deve-se ter em mente que, se o antiarrítmico escolhido não tiver o efeito desejado após a dose preconizada ter sido atingida, o tratamento deve ser a cardioversão (3). Não se deve associar antiarrítmicos. 


\begin{tabular}{|c|c|c|c|c|}
\hline \multicolumn{5}{|c|}{ Tabela III - Drogas Antiarrítmicas } \\
\hline MEDICAÇÃO & QUANDO & COMO & PORQUE & ATENÇÃO \\
\hline AMIODARONA & $\begin{array}{l}\text { TV } \\
\text { TSV } \\
\text { FA/Flutter } \\
\text { FV/TV sem pulso }\end{array}$ & $\begin{array}{l}\text { Ataque } \\
\text { - PCR - } 300 \mathrm{mg} \text { ev em bolus, segui- } \\
\text { dos de } 20 \mathrm{ml} \text { de SF; considerar } \\
150 \mathrm{mg} \text { após } 15 \mathrm{~min} \text { se não houver } \\
\text { reversão } \\
\text { - Fora da PCR - } 150 \mathrm{mg} \text { diluídos } \\
\text { em } 100 \mathrm{ml} \text {, infundidos em } 15 \\
\text { min; pode ser repetido a cada } \\
15 \text { min até conversão do ritmo. } \\
\text { Manutenção } \\
\text { - } 1 \text { mg/ min nas primeiras } 6 \mathrm{~h}, \\
\text { seguido de } 0,5 \text { mg/min nas } \\
18 \text { h consecutivas } \\
\text { Dose máxima diária - } 2,2 \mathrm{~g} \\
\text { Apresentação } \\
\text { - } 150 \text { mg/ } 3 \text { ml; ampolas }\end{array}$ & $\begin{array}{l}\text { - Diminui a condução através } \\
\text { do sistema His-Purkinje e de } \\
\text { feixes anômalos } \\
\text { - Inibe receptores alfa e beta } \\
\text { adrenérgicos e possui proprie- } \\
\text { dades vagolíticas e de bloquea- } \\
\text { dores de canais de cálcio } \\
\text { - Aumenta a duração do potencial } \\
\text { de ação em todo o te cido cardíaco } \\
\text { - No nó sinusal - reduz a FC, dimi- } \\
\text { nui a condução para o nó AV } \\
\text { e diminui a resposta ventricular }\end{array}$ & $\begin{array}{l}\text { - Hipotensão arterial é o principal efeito colateral } \\
\text { - Bradicardia (pode necessitar de marca-passo) } \\
\text { - Precipita em meio básico } \\
\text { - Diminui o metabolismo da digoxina e da warfarina } \\
\text { - Efeito aditivo com outras medicações que } \\
\text { prolongam o QT: antiarrítmicos Classe IA, } \\
\text { fenotiazínicos, tricíclicos, tiazídicos e sotalol }\end{array}$ \\
\hline ATROPINA & $\begin{array}{l}\text { Bradicardias } \\
\text { sintomáticas } \\
\text { PCR por assistolia } \\
\text { e AESP com ritmos } \\
\text { bradicárdicos }\end{array}$ & $\begin{array}{l}\text { - PCR - } 1 \mathrm{mg} \text { a cada } 3 \text { a } 5 \mathrm{~min} \\
\text { - Fora da PCR - } 0,5 \text { a } 1 \mathrm{mg} \text { a } \\
\text { cada } 3 \text { a } 5 \mathrm{~min} \\
\text { Dose máxima: } \\
\text { - } 0,03 \text { a } 0,04 \mathrm{mg} / \mathrm{kg} \\
\text { Apresentação: } \\
\text { - variável; ampolas de } \\
0,25 \mathrm{mg} / 1 \mathrm{ml}(0,5 \text { e } 1 \mathrm{mg} \\
\text { na dependência do serviço). }\end{array}$ & $\begin{array}{l}\text { - Aumenta a FC por acelerar a } \\
\text { descarga do NSA e bloqueio } \\
\text { vagal } \\
\text { - Efeito dromotrópico }\end{array}$ & $\begin{array}{l}\text { - Não utilizar doses menores do que o recomen- } \\
\text { dado (efeito paradoxal) } \\
\text { - Taquicardia, TV e extra-sístoles } \\
\text { - Cuidado em pacientes isquêmicos e em pacientes } \\
\text { com alto grau de bloqueio AV } \\
\text { - Não atua em corações transplantados }\end{array}$ \\
\hline $\begin{array}{l}\text { BETABLO- } \\
\text { QUEADORES }\end{array}$ & $\begin{array}{l}\text { - TSV estável } \\
\text { com função ven- } \\
\text { tricular preser- } \\
\text { vada } \\
\text { - Doença } \\
\text { isquêmica }\end{array}$ & $\begin{array}{l}\text { Metoprolol } \\
-5 \mathrm{mg} \text { ev lento até } 15 \mathrm{mg} \text {. } \\
\text { Iniciar por via oral } 15 \mathrm{~min} \text { após } \\
\text { a última dose. Ampolas } 5 \mathrm{mg} / 5 \mathrm{ml} \\
\text { Propranolol } \\
\text { - } 1 \mathrm{mg} \text { ev a cada } 5 \mathrm{~min} \text { até } 5 \mathrm{mg} \text {. } \\
\text { Ampolas } 1 \mathrm{mg} / 1 \mathrm{ml}\end{array}$ & $\begin{array}{l}\text { - Diminui a } \mathrm{FC} \text {, condução AV, } \\
\text { pressão arterial, consumo de } \\
\text { oxigênio } \\
\text { - Diminui arritmias induzidas por } \\
\text { excesso de catecolaminas e o } \\
\text { risco de morte súbita no IAM }\end{array}$ & $\begin{array}{l}\text { - Bradicardia } \\
\text { - Graus avançados de bloqueio AV } \\
\text { - Insuficiência cardíaca; choque cardiogênico; } \\
\text { hipotensão arterial } \\
\text { - Pode agravar ou precipitar broncoespasmo em } \\
\text { pneumopatas }\end{array}$ \\
\hline $\begin{array}{l}\text { BLOQUEADO- } \\
\text { RES DOS } \\
\text { CANAIS DE } \\
\text { CÁLCIO }\end{array}$ & $\begin{array}{l}\text { - TSV estável } \\
\text { com função ven- } \\
\text { tricular preser- } \\
\text { vada }\end{array}$ & $\begin{array}{l}\text { Verapamil - } 2,5 \text { a } 5 \text { mg ev lento. Pode } \\
\text { se repetir } 5 \text { a } 10 \text { mg após } 15 \text { a } 30 \text { min } \\
\text { da primeira dose até um total de } 20 \\
\mathrm{mg}\end{array}$ & $\begin{array}{l}\text { - Efeito inotrópico e dromotrópico } \\
\text { negativo } \\
\text { - Diminui a demanda miocárdica } \\
\text { de oxigênio }\end{array}$ & $\begin{array}{l}\text { - Bradicardia } \\
\text { - Graus avançados de bloqueio AV } \\
\text { - Insuficiência cardíaca; choque cardiogênico; } \\
\text { hipotensão arterial }\end{array}$ \\
\hline DIGITAL & $\begin{array}{l}\text { - Controle de fre- } \\
\text { quiência em paci- } \\
\text { entes com FA e } \\
\text { flutter atrial } \\
\text { - TSV }\end{array}$ & $\begin{array}{l}\text { Deslanósido } \\
\text { - } 0,8 \text { a } 1,6 \mathrm{mg} \text { em } 4 \text { doses } \\
\text { fracionadas } \\
\text { Apresentação } \\
\text { - ampolas } 0,4 \mathrm{mg} / 2 \mathrm{ml}\end{array}$ & $\begin{array}{l}\text { - Inotrópico positivo } \\
\text { - Diminui a condução através do } \\
\text { NAV }\end{array}$ & $\begin{array}{l}\text { - Toxicidade - distúrbios gástricos e visuais } \\
\text { (distorção da percepção de cores) } \\
\text { - Toxicidade aumentada em pacientes com distúrbio } \\
\text { eletrolítico (hipo ou hiperpotassemia e hipoma- } \\
\text { gnesemia) } \\
\text { - Complicações - bradicardia; graus variados de } \\
\text { BAV; intoxicação. } \\
\text { - Redução da dose - cor pulmonale, insuficiência } \\
\text { coronariana, distúrbios eletrolíticos; insuficiência } \\
\text { renal ou hepática; idosos. } \\
\text { - Interação medicamentosa - quinidina; antagonis- } \\
\text { tas de cálcio; amiodarona; espironolactona;trian- } \\
\text { tereno; eritromicina; tetraciclina, medicamentos } \\
\text { que implicam em aumento da concentração } \\
\text { sérica de digital, predispondo à intoxicação }\end{array}$ \\
\hline
\end{tabular}




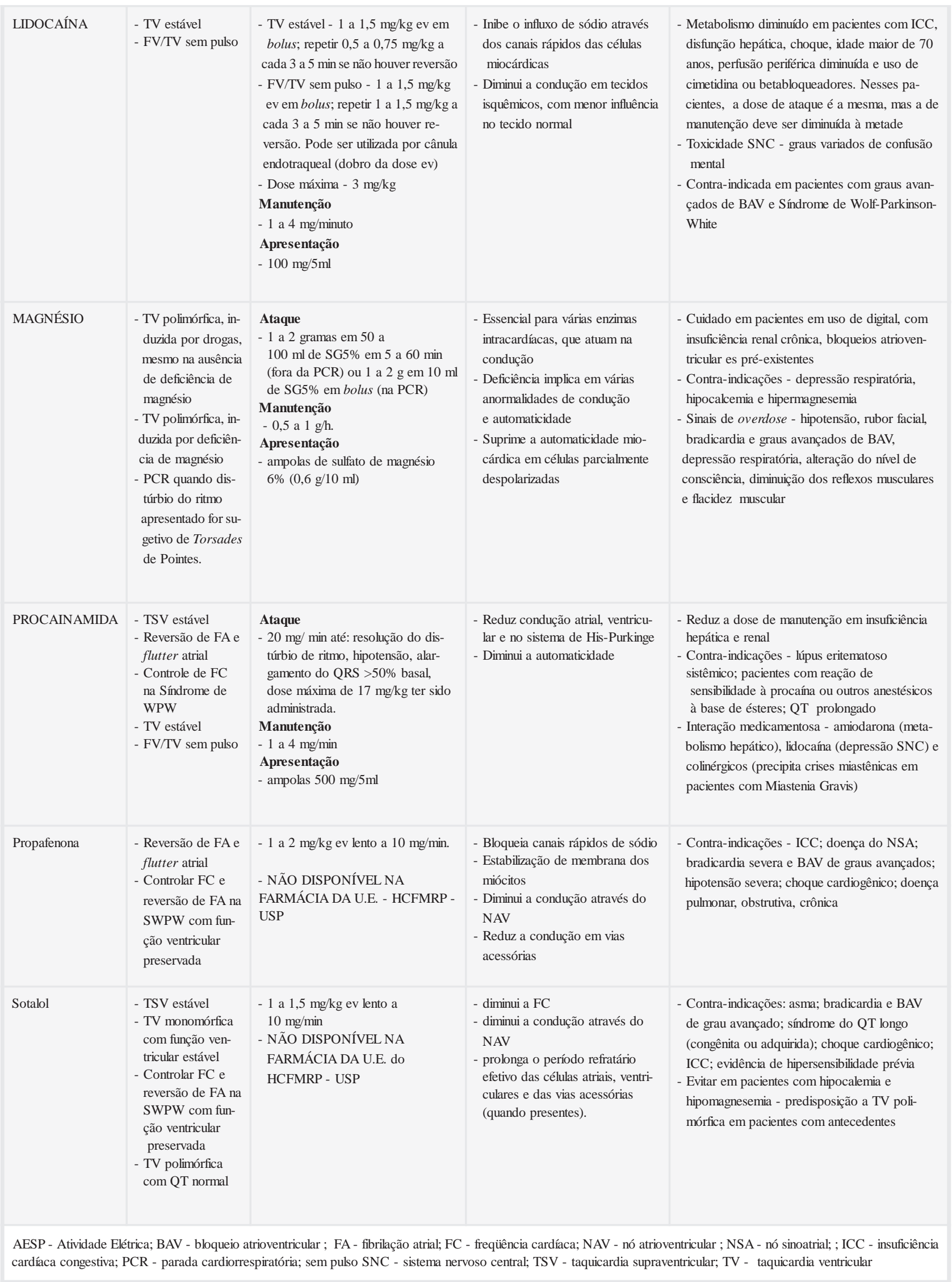




\section{3- TAQUICARDIAS}

Várias situações clínicas podem se manifestar como taquicardias.

Na vigência de instabilidade, o tratamento, qualquer que seja a etiologia da taquicardia, será a cardioversão elétrica.

A cardioversão elétrica consiste da aplicação de um choque elétrico no tórax do paciente, por meio de duas pás colocadas conforme ilustrado na Figura 4. Dispostas as pás, a corrente elétrica percorre o maior eixo do coração, despolarizando todas as células car-

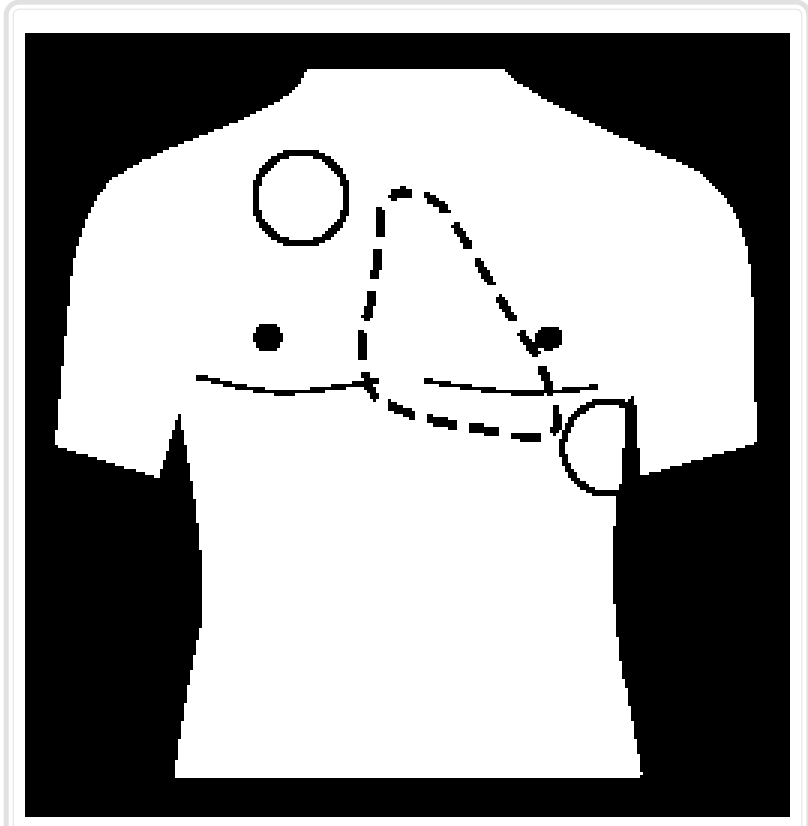

Figura 4 - Cardioversão elétrica.

1- Providencie sedação, se necessário

2- Ligue o desfibrilador.

3- Conecte os eletrodos ao tórax do paciente e ajuste a derivação no monitor.

4- Ligue o módulo de sincronização ao eletrocardiograma do desfibrilador.

5- Observe se existem marcas sobre os complexos QRS no monitor, garantindo a sincronização. Caso isso não ocorra, ajuste a derivação, o ganho ou a posição dos eletrodos.

6- Selecione o nível de energia apropriado - geralmente, iniciar com 100 Joules. Seqüência $100-200-300-360$ Joules.

7- Aplique gel condutor nas pás e posicione-as adequadamente no tórax do paciente (círculos cheios na figura). Garanta pressão adequada sobre as pás.

8- Garanta que ninguém esteja em contato direto com o paciente e avise a equipe, quando for liberar o choque.

9- Após o choque, verifique o monitor. Caso não haja reversão do ritmo, prossiga para um nível maior de energia. LEMBRE-SE DE REATIVARO MÓDULO DE SINCRONISMO A CADA CHOQUE DESFERIDO. díacas, simultaneamente. Como as células cardíacas do nó sinusal são as primeiras a se despolarizarem, a idéia do procedimento é que elas assumam o controle do ritmo cardíaco. O procedimento é doloroso, devendo ser precedido de sedação. Por ter alta eficácia, é o procedimento de escolha para pacientes instáveis, embora tenha o potencial de desencadear fibrilação ventricular, caso o choque seja aplicado durante o período refratário da repolarização ventricular (onda T). Para diminuir a chance disso, os cardioversores sincronizam o choque com o complexo QRS do paciente. Como não existe uniformidade no desenho desses aparelhos, deve-se conhecer o cardioversor disponível no serviço de emergência onde se está atuando. $\mathrm{O}$ desconhecimento do modus operandi do cardioversor pode implicar em retardo no atendimento e dano para o paciente. São necessários, também, procedimentos de segurança para a utilização do aparelho. Deve-se ter certeza de que o operador, ou qualquer outra pessoa, não esteja em contato com o paciente antes de se liberar o choque. $\mathrm{O}$ choque desferido pode ocasionar distúrbios do ritmo cardíaco, potencialmente letais, em quem o receba, por engano.

Caso o paciente não apresente critérios de instabilidade, o tratamento será guiado pelo tipo de taquicardia (Vide Figura 5). Diversas classificações podem ser empregadas em tal contexto, incluindo aquelas que utilizam o mecanismo celular gerador do distúrbio do ritmo e aquelas que utilizam o local onde a alteração ocorre. Sendo assim, a primeira classifica as taquicardias segundo aumento da automaticidade ou mecanismo de bloqueios (reentrada), enquanto a segunda categoriza os distúrbios quanto à localização ventricular ou supra-ventricular.

Do ponto de vista clínico, a segunda classificação é mais prática e amplamente utilizada. Assim, são ditas ventriculares todas as taquicardias originadas abaixo da divisão do feixe de His-Purkinje e, supraventriculares, aquelas originadas acima. De modo geral, a diferenciação entre os dois tipos de taquicardias pode ser obtida pela largura do complexo QRS, pois os distúrbios originados nos ventrículos difundem-se para o restante da massa ventricular através dos sincícios das células ventriculares, retardando o processo de condução e implicando em alargamento do QRS. Já os distúrbios supraventriculares são conduzidos ao ventrículo através do sistema de His-Purkinje, altamente especializado, que permite uma velocidade muito superior de propagação do estímulo, o que implica em complexos ventriculares estreitos. No entanto, 


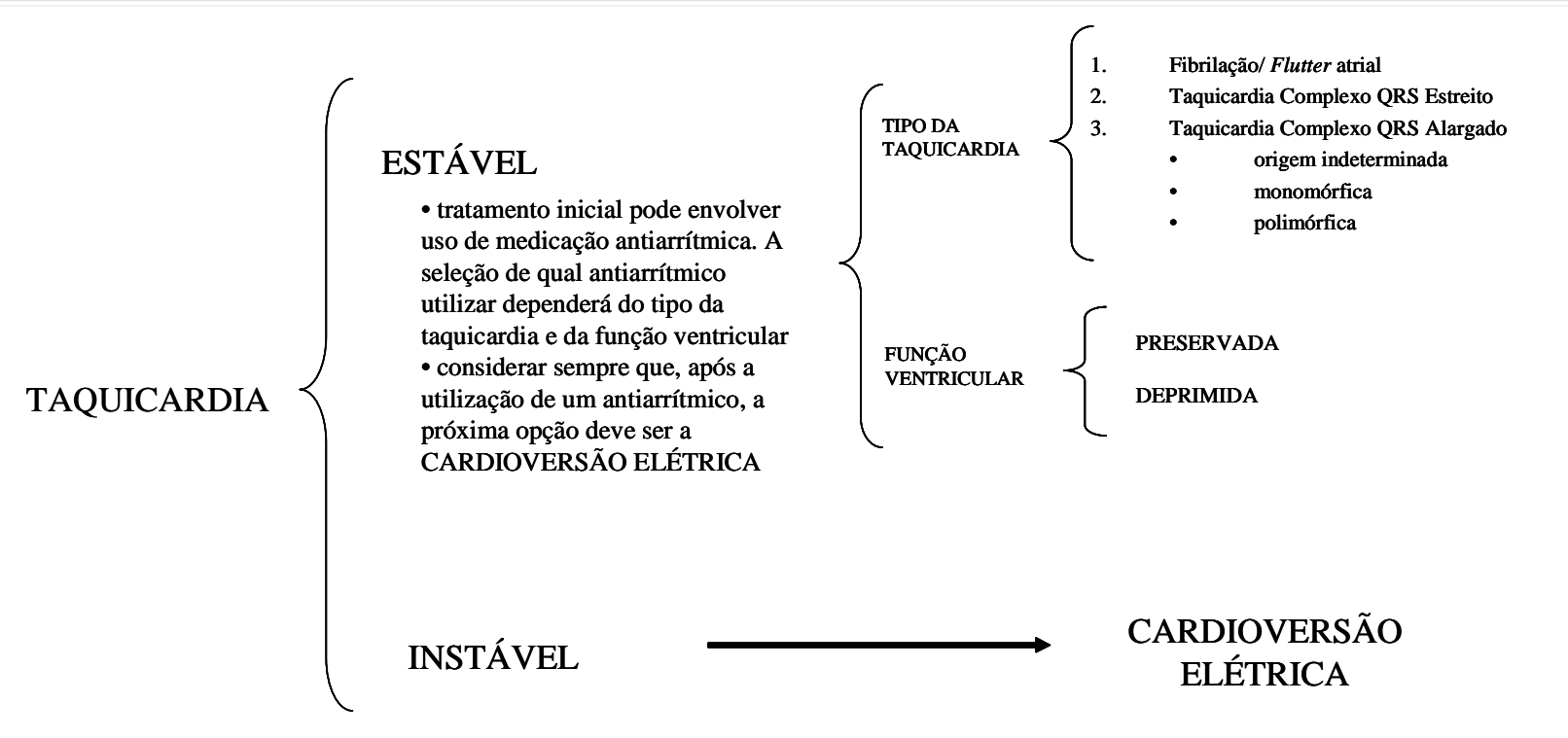

Figura 5 - Critérios para intervenção terapêutica, em situações de taquicardia.

existem exceções a essa regra, como, por exemplo, as taquicardias supraventriculares, mediadas por feixe anômalo com condução antidrômica (Figura 6) ou nos casos de taquicardia sinusal em paciente com bloqueios de ramo esquerdo avançado. Tal fato explica a razão de toda taquicardia de complexo estreito ser supraventricular quanto à origem, embora nem toda taquicardia de complexo alargado ser de origem ventricular.

A distinção é difícil, e vários recursos têm sido empregados na literatura, como, por exemplo, os critérios de Brugada $^{(3)}$. Para facilitar o diagnóstico, alguns critérios podem ser utilizados. Em primeiro lugar, deve-se ter sempre em mente que, em 80 a $90 \%$ das situações de taquicardia de complexo QRS alargado, a origem será ventricular. Isso implica que a chance de erro de se tratar um paciente com taquicardia de complexo QRS alargado como sendo supraventricular é muito alta. Em segundo lugar, as taquicardias ventriculares são mais freqüentes em pacientes com antecedente de cardiopatia. Assim, elementos como idade (pacientes com mais de 45 anos têm maior chance de apresentar cardiopatia, como,

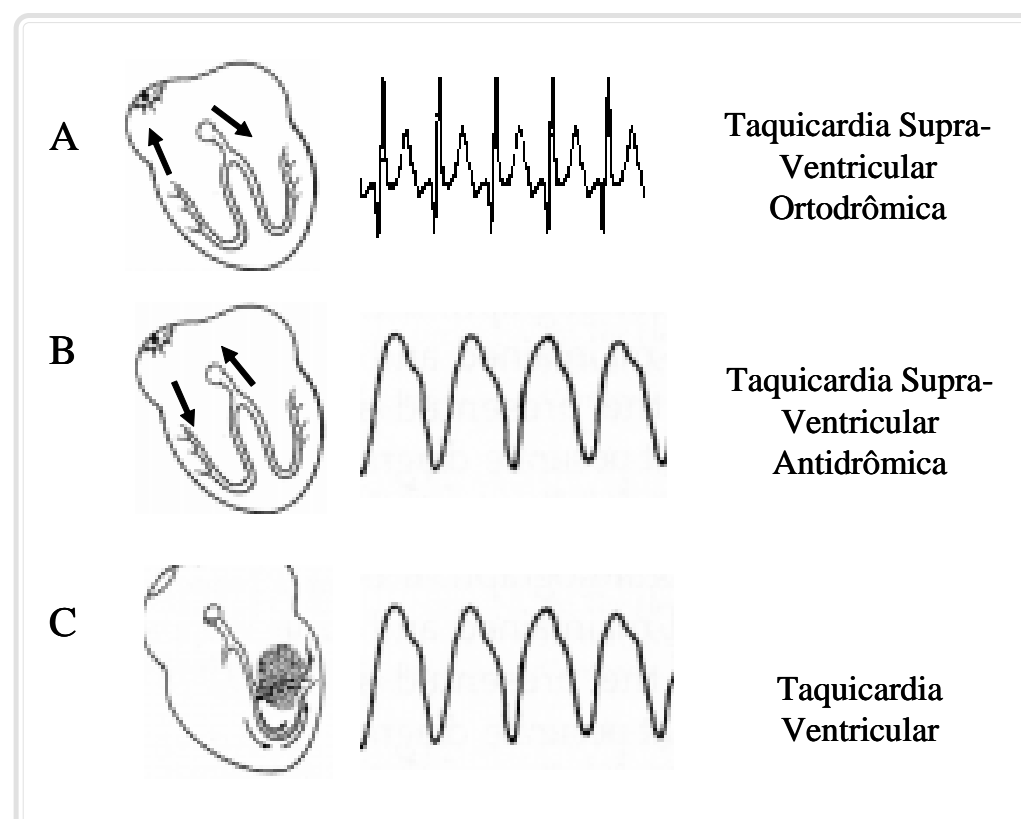

Figura 6 - Largura do Complexo QRS, de acordo com o mecanismo de origem da taquicardia. Nas situações $A$ e $B$, a gênese da taquicardia envolve os átrios e os ventrículos, e a propagação do estímulo envolve o sistema His-Purkinje, enquanto que, na situação $C$, a gênese da taquicardia é no ventrículo. Embora as situações B e C tenham mecanismos distintos, sua apresentação eletrocardiográfica é similar, com complexos QRS alargados. 
prévia ao evento, etc) sugerem que o paciente seja cardiopata e, portanto, a chance de aquela taquicardia de complexo QRS alargado, de origem ventricular, ser muito maior. Em terceiro lugar, está o fato de que, muitas das medicações antiarrítmicas, conforme já ressaltado, anteriormente, apresentam uma série de efeitos colaterais sobre o sistema cardiovascular. Todas essas considerações fundamentam a diretriz de que toda taquicardia de complexo QRS alargado, salvo exceções onde um especialista esteja presente ou se tenha certeza de que se trata de uma taquicardia supraventricular antidrômica, deve ser conduzida como de origem ventricular.

Após determinar o tipo de taquicardia, o tratamento, quando o paciente não se apresenta instável, poderá ser realizado com medicações antiarrítmicas. Observe, como se pode depreender da Figura 3, que as medicações antiarrítmicas são de uso exclusivo para as taquicardias estáveis. Não se utilizam medicações antiarrítmicas em situações de bradicardia.

As taquicardias supraventriculares, geralmente, apresentam-se com complexos QRS estreitos. Envolvem uma ampla variedade de arritmias, que são ocasionadas por dois mecanismos fisiopatológicos distintos, cujo reconhecimento é importante para a conduta terapêutica a ser adotada: a reentrada e o aumento do automatismo ${ }^{(4)}$.

As taquicardias mediadas por feixe anômalo, como a Síndrome de Wolf-Parkinson-White, e a dupla via nodal são exemplo de taquicardias supraventriculares mediadas por mecanismo de reentrada. Geralmente, são encontradas em pacientes jovens, com episódios de taquicardia prévios e sem cardiopatia estrutural conhecida. Essas taquicardias podem ser interrompidas por manobra vagal e por uso de adenosina endovenosa, bem como respondem à cardioversão elétrica.

A taquicardia atrial multifocal ${ }^{(5)}$ e a taquicardia juncional são exemplos de aumento do automatismo. São encontradas em pacientes com cardiopatia estrutural (pós-operatório de cardiopatias congênitas, isquemia, etc) ou pneumopatias (Doença Pulmonar Obstrutiva Crônica). Não respondem à manobra vagal, adenosina ou cardioversão. Comparativamente ao flutter e à fibrilação atrial, são de incidência mais rara.

Apesar de a história clínica auxiliar na distinção, em um número não desprezível de casos, a diferenciação eletrocardiográfica é difícil. As técnicas descritas para documentação do distúrbio do ritmo, previamente descritas, podem ser de grande valia. Outras duas técnicas podem ser úteis: a manobra vagal e o uso de adenosina endovenosa. Existem diversos tipos de manobras vagais, dentre as quais, a mais conhecida e de utilidade clínica mais documentada é a massagem do seio carotídeo. Consiste em estímulo do seio carotídeo, inicialmente à direita $\mathrm{e}$, em caso de insucesso, à esquerda (nunca simultaneamente), no intuito de estimular, via conexões pontinas, o nervo vago, ocasionando diminuição da passagem do estímulo cardíaco através do nó atrioventricular . Antes de se tentar a manobra, deve-se auscultar, com cuidado, a área, em busca de sopros que indiquem a presença de obstruções por placas de ateroma. A presença de sopro carotídeo implica em risco de tromboembolismo cerebral, na eventualidade da massagem, constituindo contra-indicação à mesma. A segunda técnica é o uso de adenosina endovenosa (Vide Tabela III). O término da taquicardia frente à qualquer uma das duas técnicas implica que o mecanismo de ação seja o de reentrada. A ausência de resposta, no entanto, não descarta a possibilidade.

Após se determinar o diagnóstico presuntivo para a taquicardia supraventricular, deve-se escolher a forma de tratamento. Nos casos estáveis, em que não tenha havido reversão com a manobra vagal ou adenosina, o próximo passo é a escolha de uma medicação antiarrítmica, que segue os princípios previamente descritos. Em pacientes com função cardíaca preservada, podemos utilizar betabloqueadores, bloqueadores dos canais de cálcio ou amiodarona, enquanto que somente esta última pode ser utilizada nos pacientes com função deprimida.

As taquicardias ventriculares apresentam complexos alargados, ao eletrocardiograma. Está sempre implícito que se trata de distúrbios do ritmo cardíaco potencialmente letais e que devem ser revertidos prontamente. Seguindo esse princípio é aceitável que se opte pela cardioversão elétrica mesmo naqueles casos em que o paciente não apresente critérios de instabilidade. Pode-se, no entanto, nos pacientes estáveis, realizar tentativa com medicações antiarritmicas. A escolha do antiarrítmico depende de dois fatores: tipo de taquicardia e função ventricular ${ }^{(6)}$.

Existem dois tipos de taquicardia ventricular: a monomórfica e a polimórfica (Figura 7). A taquicardia ventricular monomórfica é, geralmente, observada em pacientes com cardiopatia estrutural, está freqüentemente relacionada ao mecanismo de reentrada, e responde ao uso de antiarrítmicos. Naqueles pacientes com função ventricular preservada, pode-se utilizar procainamida, sotalol, amiodarona ou lidocaína, enquanto que, naqueles com função deprimida, somente a 


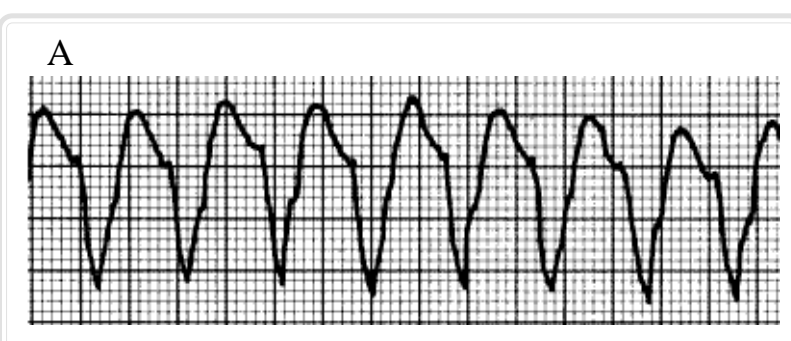

B

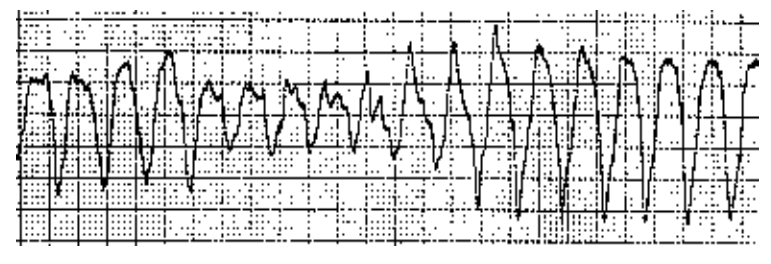

Figura 7 - Taquicardias ventriculares.

A - taquicardia ventricular monomórfica.

B - taquicardia ventricular polimórfica

amiodarona ou lidocaína são aceitáveis. A taquicardia ventricular polimórfica, geralmente, é observada em pacientes com distúrbios eletrolíticos (hipocalemia e hipomagnesemia) ou em pacientes com alterações genéticas (Síndrome do QT Longo) e seu tratamento consiste na correção do distúrbio precipitante, no uso de sulfato de magnésio endovenoso e em overdrive através de marca-passo transvenoso temporário. Embora respondam à cardioversão, como o mecanismo responsável pela sua gênese é o aumento do automatismo, a chance de recorrência é muito elevada. O uso de medicações antiarrítmicas também é aceitável no contexto, seguindo as mesmas opções da taquicardia ventricular monomórfica para os casos de função ventricular deprimida. Nos casos em que a função ventricular esteja preservada, o conhecimento prévio do intervalo QT, no eletrocardiograma, pode ser útil. Aqueles com intervalo QT normal permitem o uso de betabloqueadores, lidocaína, amiodarona, procainamida ou sotalol, enquanto que o alargamento do intervalo QT direciona o tratamento para magnésio, isoproterenol, fenitoína e lidocaína.

A amiodarona vem se destacando como um antiarrítmico seguro nas taquicardias tanto supra quanto ventriculares. É importante ressaltar que seu uso é facultado em todos os tipos de taquicardia, com exceção da taquicardia polimórfica em que se suspeita de intervalo QT prolongado.

Considerando-se o efeito pró-arrítmico que qualquer medicação antiarrítmica apresenta, conforme discutido anteriormente, em qualquer situação de taqui- cardia estável (ventricular ou supraventricular) não se deve adicionar um segundo antiarrítmico após o primeiro aplicado. Caso um antiarrítmico tenha sido administrado em dose máxima e não se tenha obtido a reversão do distúrbio do ritmo cardíaco, o próximo passo deve ser a cardioversão elétrica e não a administração de um segundo anti-arrítmico.

\section{4 - BRADICARDIAS}

Os distúrbios do ritmo cardíaco que se manifestam como bradicardias seguem as mesmas considerações gerais, discutidas previamente. É fundamental considerar se o distúrbio detectado é o responsável pelo quadro clínico apresentado e se ele é primário ou secundário.

As bradicardias podem implicar em comprometimento do débito cardíaco, com implicações clínicas já ressaltadas na Tabela II. Seu tratamento depende de dois fatores: da presença de instabilidade e do tipo de distúrbio de ritmo. A presença de instabilidade indica intervenção, que deve seguir a seguinte ordem: atropina, marca-passo transcutâneo, dopamina, epinefrina e isoproterenol. Para orientações sobre o uso das medicações, vide Tabela III e Figura 8. O marca-passo transcutâneo é um dispositivo acoplado a alguns cardioversores que, através de placas adesivas ao tórax, em posições similares às demonstradas na Figura 4, permite a captura do ritmo cardíaco pela estimulação elétrica seriada. É de fácil colocação e manuseio, seguindo as mesmas orientações fornecidas, anteriormente, para o uso dos cardioversores. O uso das medicações e do marca-passo transcutâneo, nas bradicardias sintomáticas (instáveis), é considerado como uma "ponte" até a colocação do marca-passo transvenoso provisório, ou seja, são medidas paliativas.

Nos pacientes bradicárdicos assintomáticos, a intervenção dependerá do tipo de distúrbio do ritmo cardíaco. Alguns distúrbios refletem maiores danos ao sistema de condução cardíaco, com maior chance de evoluírem para situações potencialmente letais, justificando maior agressividade no tratamento escolhido. Assim, nos pacientes com bloqueio atrioventricular de segundo grau, tipo II, e de terceiro grau, está indicado o implante de marca-passo transvenoso, provisório, independente da presença ou ausência de sintomas. O marca-passo transcutâneo pode ser utilizado como "ponte", também nessas situações.

A Figura 9 apresenta um método simplificado para a identificação dos bloqueios atrioventriculares. 


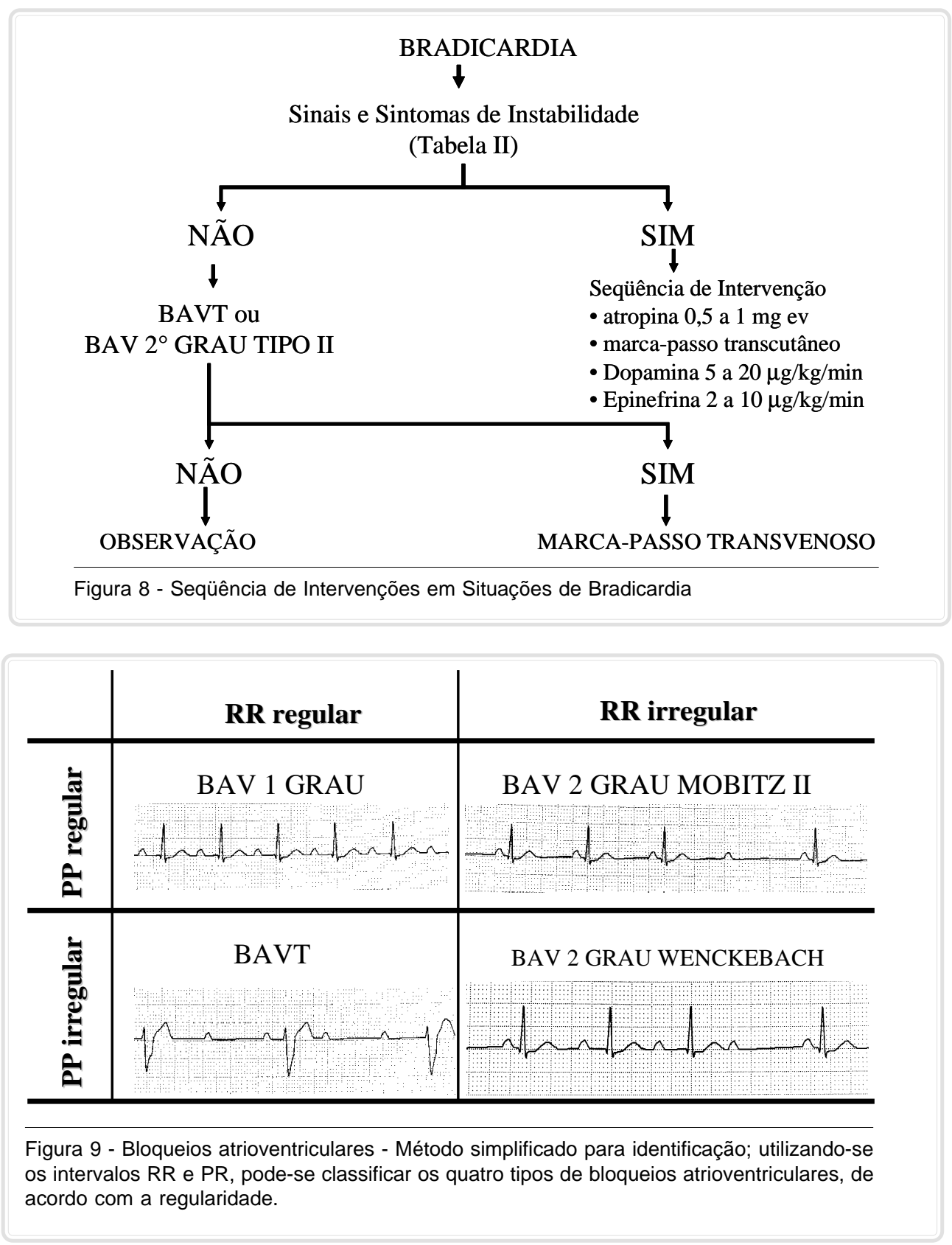

\section{5- FIBRILAÇÃO E FLUTTER ATRIAL}

A fibrilação e o flutter atrial quando comparados às situações previamente discutidas, apresentam algumas peculiaridades que diferenciam seu tratamento. São distúrbios do ritmo cardíaco extremamente prevalentes na população. Sua presença implica em perda da contração atrial efetiva, proporcionando estase sangüínea e a formação de coágulos intracavitários. Os coágulos podem se descolar da parede atrial e embolizar para a circulação, ocasionando quadro clínico variável, na dependência do local onde o êm- bolo se alojar. Esse é o mecanismo que pode ser responsável por casos de necrose de extremidades, amaurose, e perda de função renal, entre outros, mas, sem dúvida nenhuma, a complicação mais temível é o acidente vascular cerebral isquêmico. Pacientes com fibrilação atrial apresentam chance cinco vezes maior do que a população em ritmo sinusal, de desenvolver acidente vascular cerebral isquêmico. Esse risco é atingido após $48 \mathrm{~h}$ da instalação do distúrbio de ritmo, fato que deve ser considerado no tratamento de pacientes em tal situação.

Esses distúrbios do ritmo cardíaco podem ocor- 
rer em corações estruturalmente normais, mas, na grande maioria dos casos, instalam-se em pacientes com cardiopatia estrutural, principalmente valvulopatia mitral, e pneumopatia. Frente a tal dado, as considerações anteriores sobre função ventricular devem ser mantidas em mente.

Podem se instalar em pacientes com pré-excitação ventricular (pacientes portadores de feixe anômalo de condução, como na Síndrome de WolfParkinson-White) e, nesse caso, em particular, implicam em morbimortalidade elevada, devendo ser corrigidos, prontamente, com cardioversão elétrica.

Os objetivos do tratamento são: controle da frequiência cardíaca, reversão para o ritmo sinusal e prevenção de fenômenos tromboembólicos. Para se obter tais objetivos, deve-se levar em consideração se o paciente está instável ou não, função ventricular, presença de pré-excitação e duração da instalação do distúrbio. Pacientes instáveis devem ser submetidos imediatamente à cardioversão elétrica. Mesmo que apresentem risco de fenômenos tromboembólicos, a instabilidade implica em elevada morbimortalidade.

Se a duração da instalação do distúrbio do ritmo for maior do que $48 \mathrm{~h}$, há risco aumentado de fenômenos tromboembólicos, limitando o uso de medi- cações que revertam o distúrbio do ritmo para ritmo sinusal. Nesses casos, se o paciente estiver estável, o objetivo deve ser controle da freqüência e a anticoagulação. Para tais fins, pode-se utilizar betabloqueadores e bloqueadores de canais de cálcio, se a função ventricular for preservada, e digoxina, diltiazem (com cuidado!) e amiodarona, caso se encontre deprimida. Na presença de pré-excitação, deve-se evitar digoxina, adenosina, betabloqueadores e antagonistas dos canais de cálcio, restando, como opção, amiodarona, flecainide, procainamida, propafenona e sotalol, embora a depressão da função ventricular torne a amiodarona a única escolha.

Quando a duração da instalação da fibrilação ou do flutter atrial for menor do que $48 \mathrm{~h}$, os objetivos de tratamento passam a incluir a reversão para ritmo sinusal. Isso pode ser obtido por cardioversão elétrica, que pode ser utilizada independente da função ventricular ou da existência de pré-excitação. Se se optar por medicações antiarrítmicas, as alternativas são amiodarona, flecainide, propafenona e procainamide (sotalol também é opção nos casos em que exista préexcitação ventricular), quando a função ventricular for preservada. Nos casos de depressão da função ventricular, as alternativas se restringem à amiodarona.

PAZIN FILHO A; PYNTIÁ JP \& SCHMIDT A. Cardiac arrithmias. Medicina, Ribeirão Preto, 36: 151-162, apr./dec. 2003.

ABSTRACT - The fundamental concepts for emergency room cardiac arrithmias management are discussed. The treatment of tachy and bradycardias, as well as atrial fibrillation and atrial flutter are reviewed in greater detail due to their prevalence.

UNITERMS - Arrithmia. Tachycardia. Bradycardia. Atrial Fibrillation. Atrial Flutter.

\section{REFERÊNCIAS BIBLIOGRÁFICAS}

1 - RODEN DM. Risks and benefits of antiarrhythmic therapy. $\mathbf{N}$ Engl J Med 331: 785-791, 1994.

2 - MOREIRA DAR. Abordagem clínica das arritmias cardíacas. In: MOREIRA DAR Arritmias cardíacas: Clínica, diagnóstico e terapêutica. Artes Médicas, São Paulo,1995, p 2638.

3 - BRUGADA P; BRUGADA J; MONT L; SMEETS J \& ANDRIES EW. A new approach to the differential diagnosis of a regular tachycardia with a wide QRS complex. Circulation 83: 16491659, 1991.
4 - GANZ LI. \& FRIEDMAN PL. Supraventricular tachycardia. N Engl J Méd 332: 162-173, 1995.

5 - SAOUDI N; COSIO F; WALDO A; CHEN S; IESAKAY; LESH M; SAKSENA S; SALERNO J \& SCHOELS W. Classification of atrial flutter and regular atrial tachycardia according to electrophysiologic mechanism and anatomic bases: a statement from a joint expert group from the working group of arrhythmias of the European Society of Cardiology and the North American Society of Pacing and Electrophysiology. J Cardiovasc Electrophysiol 12: 852-866, 2001.

6 - CHAKKO S \& KESSLER KM. Recognition and management of cardiac arrhythmias. Curr Probl Cardiol 20: 54-117, 1995. 